\title{
LAS PERSONAS, EL PERSONALISMO Y LA CONSTITUCION PERUANA DE 1979
}

\author{
Carlos Fernández Sessarego
}

I. La derogada Constitución de 1933 y el vigente Código Civil de 1936 en relación con la persona.

La derogada Constitución Peruana de 1933 no contenia ninguna especifica referencia a la persona humana en cuanto tal ni definia su relación con el Estado y la sociedad. El constituyente de 1933 se preocupó por diseñar normativamente los mecanismos del Poder descuidando la regulación juridica tendiente a la protección de la persona a cuyo servicio, precisamente, se constituye el Estado.

El constituyente de 1933 no tuvo presente o no valorizó debidamente el preponderante rol de la persona en sociedad y frente al Estado, razón por la cual, probablemente, se abstuvo de incluir en su texto los pertinentes principios juridicos rectores de tal situación. Es por esta notoria carencia el que no se encuentre en su articulado una orgánica y sistemática regulación de los derechos fundamentales de la persona. Sólo a través del art. 24 de dicho cuerpo legal se hacia una alusión a la libertad juridica al prescribirse que "nadie está obligado a hacer lo que la Ley no manda, ni impedido de hacer lo que ella no prohibe". A esta declaración de carácter técnico, a nivel lógico-normativo, se agregaban, en forma desarticulada y asistemática, algunas de las llamadas $-o$ pretendidamente 
llamadas- libertades como las de conciencia'y creencia, prensa, trabajo, comercio e industria, colocadas ellas ya sea bajo el rubro de "Garantias Nacionales y Sociales" o el de "Garantias Individuales". En este último capitulo se insertaban, asi mismo, algunos derechos como el de la inviolabilidad del domicilio, el no ser compelido al trabajo contra expresa voluntad, el de no permanecer detenido por más de veinticuatro horas sin mandamiento de juez competente, el de igualdad ante la ley, el de la inviolabilidad de la correspondencia.

El vigente Código Civil de 1936 tampoco hace mención, dentro de su articulado, a la persona humana. La atención del codificador se centró en la extensa y técnica regulación de los aspectos patrimoniales de la persona prescindiendo en absoluto de todo cuanto tuviera que hacer con la normación de sus derechos fundamentales.

La ausencia de una legislación que situara adecuadamente a la persona y sus 'derechos fundamentales en los más importantes cuerpos de leyes de la República -como la Constitución y el Código Civil_ originó el que se alzaran, en la década del 60, algunas aisladas voces reclamando tanto la dación de un nuevo Códigó Civil, concorde con los tiempos', como ae una nueva Constitución que regulara, no sólo la temática concerniente a la persona, sino que asumiera, con una técnica legislativa depurada, las crecientes expectativas de la comunidad nacional por una más justa organización social y por un Estado'funcional y moderno (1).

Es a partir de la segunda mitad de la década del 40 que adquiere consistencia en el Perú la preocupación por elaborar una teoria de la persona bajo el influjo del existencialismo, en sus varias expresiones, del humanismo marxista que recién se insinuaba, y de los nacientes personalismos, mayoritariamente de inspiración

(1) En "Consideraciones sistemáticas preliminares para la revisión del Libro Primero del Código Civil" (Lima, 1964) el autor de este articulo insistia sobre la necesidad de dictar tanto una nueva Constitución como un moderno Código Civil. Esta misma propuesta fue reformulada en una conferencia dictada en noviembre de 1968 dentro de un ciclo dedicado, precisamente, a la Constitución Peruana, y que organizara el Colegio de Abogados de Lima. Debe señalarse que la gran mayoria de los juristas no concordaba con este planteamiento. 
cristiana. Este movimiento de pensamiento, esta creciente inquietud filosófica, se enriquece en las décadas subsiguientes en las que se acentua la investigación, la 'enseñanza y la divulgación de los nuevos planteamientos sobre el hombre y la existencia tanto a través de la cátedra universitaria como mediante diversas publicaciones (2).

II. El tratamiento de los derechos fundamentales de la persona en el Libro Primero "De las Personas" del proyecto del nuevo Código Civil Peruano.

Aprovechándose de una ocasional coyuntura, y como eco del movimiento personalista o humanista que comenzaba a hacerse presente en los ambientes intelectuales del Perú de los años sesenta, se constituyó, en maszo de 1965, la Comisión Reformadora del Código Civil con la tarea de proyectar un texto que otorgara a la regulación de los derechos fundamentales de la persona la relevancia y la prioridad que les corresponde dentro del ordenamiento juridico. La Comisión inició sus trabajos con suma dedicación y prontamente concluyó con los proyectos del llamado Título Preliminar y del Libro Primero "De las Personas". Las vicisitudes políticas obligaron a largos paréntesis en el trabajo del grupo de juristas designado al efecto, lo que no ha impedido que en la actualidad se haya concluido con la ardua y fatigosa tarea y se encuentre ya en prensa el proyecto total del Código.

Las tesis personalistas son recogidas, por primera vez a nivel legislativo, en el proyecto del Libro Primero, "De las Personas", del nuevo Código Civil y en su consiguiente Exposición de Motivos, ambos concluidos en 1967 y tardiamente publicados en 1977. Tal vez habria que encontrar en estos textos el precedente normativo inmediato del Capítulo 1 del Título I de la Constitución

(2) La década del 60 fue particularmente fecunda en publicaciones que se referian fundamentalmente a la persona. Bastaria citar, entre otros: Carlos Fernández Sessarego, "La Noción Juridica de Persona", Imp. de la Universidad de San Marcos, Lima, 1968 (segunda edición); Mario Alzamora Valdez, "La Filosofia del Derecho en el Perü", Edit. Minerva, Lima 1968; Augusto Salazar Bondy, "Entre Escila y Caribdis", Casa de la Cultura del Perú, Lima, 1969; Francisco Miró Quesada, "Humanismo y Revolución", Casa de la Cultura del Perú, Lima, 1969. 
Peruana vigente a partir de julio de 1980 y que se refiere a los derechos fundamentales de la persona (3).

En la Exposición de Motivos del proyecto de Libro Primero del Código Civil se señala que en la redacción de su articulado, aparte de diversos textos legislativos y jurisprudenciales y del lo. gico auscultamiento de realidad nacional, ha gravitado una acentuada concepción personalista del Derecho, explicándose que dicha inspiración o tendencia "es concorde con una visión del mundo en la que el hombre es un fin en si mismo", lo que hace que la persona se constituya, en cuanto sujeto del Derecho, en "centro y término de las relaciones juridicas, en eje insustituible del Derecho" (4).

Dentro del marco teórico aludido en el párrafo precedente el citado Libro Primero del proyecto de Código Civil desarrolla sistemáticamente los más importantes derechos fundamentales de la persona -más conocidos en la doctrina civilista como derechos de la personalidad - bajo el entendido que, de acuerdo con una concepción personalista, lo que se trata de tutelar jurídicamente es el ser y las maneras de ser de la persona en tanto ontológicamente libre. Se pretende, según se expresa, utilizar el Derecho del hombre en el proceso abierto del tiempo, de acuerdo a su personal proyecto vital, "autoconstituyéndose en la historia, apoyado en la realidad de su cuerpo y de su pasado". Pero, simultáneamente, la protección jurídica dispensada a la persona es una exigencia comunitaria dirigida a que todas las personas, "en cuanto entes coexistenciales, puedan solidariamente contribuir en óptimas condiciones psicosomáticas, al bien común, a la consecución de una sociedad justa en la que los hombres se integren mediante el trabajo" (5).

(3) El proyecto del Libro Primero "De las Personas" y su consiguiente Exposición de Motivos fueron publicados en la "Revista de Jurisprudencia Peruana", No 379, abril de 1977, págs. 501 a 523 y № 400, mayo de 1977, de págs. 629 a 650. La Comisión Reformadora del Código Civil fue creada por Decreto Supremo No 95 de $1^{\text {9 }}$ de marzo de 1965. La redacción del anteproyecto del Libro Primero "De las Personas" y de su consiguiente Exposición de Motivos fueron encomendados, en calidad de ponente, al autor de esta publicación.

(4) Rev. de Jurisprudencia Peruana, No 398, pág. 383.

(5) Rev. de Jurisprudencia Peruana, No 398, pág. 391. 
Coincidiendo principalmente con el pensamiento de Mounier en la Exposición de Motivos antes referida, se indica que el conjunto de derechos fundamentales de la persona tienden a alejar "lo más posible al hombre de las alienaciones que sin destruir la libertad -hecho que se da sólo con el aniquilamiento biológico del ser humano-, lo degradan o lo reducen a limites indignos de la persona humana" (6). Es por ello que el derecho justo debe coadyuvar a que el hombre pueda cumplir su función liberadora dentro de su inevitable contingencia. La ley deviene asi, "piloteada por la libertad, en instrumento de nuestra liberación continua y de nuestra integración progresiva en un universo de personas morales" (7). Es éste el sentido último que subyace en el articulado del Proyecto de Libro Primero del Código Civil Peruano aún en trance de aprobación.

Al redactarse el proyecto del libro "De las Personas" se tuvo conciencia que la libertad - que sólo se la "capta desde dentro y de raiz, surgiendo con ella" - no se gana "contra los determinismos naturales, se conquista sobre ellos, pero con ellos" (8), por lo que el combate de la libertad es aventura incesante, permanente y continua, que no conoce pausa ni reposo. Como sostiene el propio Mounier, la batalla de la libertad no conoce fin. $\mathrm{Si}$ bien es necesario que el Estado proteja los derechos fundamentales de la persona mediante el ordenamiento jurídico, ello no sig nifica, en última instancia y dada la característica radical de la persona como ser libre - y por tanto, lábil, en movimiento-, el que se conceda al hombre desde el exterior, por virtud de una Constitución o de un Código, tales derechos o libertades. L.as iibertades, como sostiene lúcidamente Mounier, "no son sino oportunidades abiertas al espiritu de libertad" (9). No obstante lo

(6) Rev. de Jurisprudencia Peruana, No 398, pág. 392.

(7) E. Mounier, "El Personalismo", Ed. Eudeba, Buenos Aires, 1962, pág. 46.

(8) E. Mounier, ob. cit., pág. 36. Para el autor es la "persona quien se hace libre, después de haber elegido ser libre". Es decir, que la libertad no está dada o constituida, por lo que la persona debe penetrar "audazmente en la experiencia de la libertad". La libertad le es propuesta al hombre como un don por lo que la persona la acepta o la rechaza.

(9) E. Mounier, ob. cit., pág. 39 Siendo la libertad fuente viva de ser, el hombre es interiormente libre -instancia de la decisión- cuando quiere, por lo que las libertades concretas no son indispensables en este intimo trance. 
expuesto, en mérito a la naturaleza tridimensional del Derecho, y desde un punto de vista técnico, tales derechos y libertades deben ser consagrados a nivel lógico-normativo a fin de poder ser jurídicamente invocados por la persona. La llamada "Lucha por el Derecho" se reduce, en fin, a transformar en reglas juridicas los derechos fundamentales del hombre como aspiración de la comunidad y a lograr que el Estado, una vez integradas dentro del ordenamiento juridico, no las transgreda y las haga respetar en la vida social.

Los derechos fundamentales, una vez asumidos por el ordenamiento juridico, pretenden otorgar al hombre el máximo de facilidades y de garantías para que pueda - si asi lo decide en cuanto ser libre y ello es posible - realizarse como persona, asegurándole normativamente "las libertades", creando jurídicamente las condiciones económicas, 'sociales, biológicas, culturales y politicas, que le permitan desenvolverse según su intima vocación.

Dentro de los lineamientos enunciados en el Proyecto on cuestión se 'regula, a través de 34 artículos, el goce de los derechos civiles, el derecho a la vida, a la libertad, a la honra, a la integridad física, a la intimidad de la vida privada en todos sus aspectos, a la imagen, a la identidad. Todo ello, claro está, en el mar. co y dentro de los limites, del Derecho Civil.

III. El personalismo como tendencia informadora del Proyecto de Código Civil y de la Constitución de 1979.

Cuando en estas páginas nos referimos al personalismo hacemos alusión, principalmente, a la sugerente y diáfana versión de Emmanuel Mounier, sin que ello signifique excluir o no considerar otros aportes que se mueven en la misma dirección, que confluyen en similar propósito y que han enriquecido, a través del tienpo, una correcta visión del hombre en cuanto persona. El personalismo como corriente de pensamiento comporta una posición que, si bien se ha perfilado nitidamente en años recientes, entronca con una antigua y larga tradición cuya afirmación central es la existencia de personas libres y creadoras. $Y$ dentro de esta secuencia temporal es al cristianismo al que se debe radicalmente 
la reinvindicación del hombre en cuanto persona. Constituye asi un insoslayable y permanente punto de referencia, un hito presente en cualquier elaboración de una filosofia sobre el ser humano.

Mounier sostiene que el personalismo, aparte de ser una actitud, es una filosofia. $Y$ bien sabemos que la filosofia se opone a todo lo que pudiera considerarse como un sistema cerrado de ideas, aunque tales ideas requieran de una sistematización y de un orden. La filosofia, en cuanto bagaje de ideas, supone necesariamente una propuesta abierta a la meditación, a la reflexión, al repensamiento de parte de cada uno. Sólo así concebimos y entendemos la tarea filosófica. Como misión y aventura ciel pensamiento y la imaginación del hombre, capaz de pensar por sí mismo lo pensado por otros, pensamiento cargado de propias e irrepetibles resonancias en una vivencia que no es intercambiable. Si el quehacer filosófico es por naturaleza una propuesta y una incitación, con mayor razón será contrario a toda inmóvil articulación, a todo pensamiento acabado. Con mayor razón si su objeto es la persona que, en cuanto ser libre y creador, es imprevisible, dinámico, lábil, irrepetible como experiencia, movimiento continuo.

De lo expuesto en el párrafo anterior se deduce, como anota el propio Mounier, que aunque se hable por comodidad del personalismo es dable tener en cuenta que existen personalismos. por lo que es conveniente y necesario asumir sus diversas modalidades. Es así que en el repertorio de los personalismos nos encontramos con unos de raigambre cristiana y con otros de formulación agnóstica. Al lado de ellos, con variadas expresiones, hallamos lo que suele llamarse humanismos y con los que se advierten importantes coincidencias. $Y$ aunque unos $y$ otros puedan diferir en su estructura más profunda, más intima, sin mbargo todos ellos se despliegan en base a ciertas afirmaciones fundamentales y elaboran un tipo de pensamiento común, lo que permite el que se les pueda vincular y considerar bajo una misma etiqueta, bajo el común denominador del personalismo. Mounier corrobora todas estas elucu. braciones cuando señala que al utilizar el vocablo personalismo para identificar su línea de pensamiento no pretende con ello la "creación de una escuela, la apertura de una capilla, la invención de un sistema cerrado". A lo más, concluye, se trata de testimoniar una convergencia de voluntades $y$ de ponerse a su servicio 
"sin afectar su diversidad, para buscar los medios de pesar eficazmente sobre la historia" (10).

El planteamiento abierto del personalismo, tal como lo hemos mostrado, explica el que haya podido ser recogido como cuerpe de ideas, como hilo conductor, como sustento de aquello que de más medular contiene la Constitución Peruana de 1979. Han confluido en su recepción, para su ulterior consagración normativa, constituyentes de diversa raigambre ideológica pero identificados solidariamente en considerar a la persona como fin supremo de la sociedad y del Estado, digna de ser materia de la más amplia y absoluta protección juridico-normativa. Al fin de cuentas, más allá de algunas $\longrightarrow$ muchas - crueles realidades históricas, el personalismo es asumido por las mentes más lúcidas, se abre terreno entre los pensadores y filósofos, se impone a la consideración y a la voluntad de los pueblos más maduros. Constituye un rumbo, un derrotero a transitar, una siempre más creciente aspiración comu. nitaria.

La desorientación que a menudo reina en lo tocante a la cabal comprensión de un planteamiento de tipo personalista nos obliga a algunas precisiones complementarias. Ellas están dirigidas a mostrar que la civilización que se persigue al sostener e implementar las ideas hasta acá expuestas, es a la par personalista y comunitaria. Y ello si se tiene en consideración que la existencia es co-existencia, es decir que una estructura fundamental del ser del hombre es el "ser-en-el-mundo", dicho a la manera de Heidegger. Todo modo de existencia es un modo de coexistencia. El estar en el mundo comporta estar con "otros", coexistir. La persona es asi una "presencia dirigida hacia el mundo y las otras personas, sin limites, mezclada con ellos en perspectiva de universalidad". Como acota Mounier la persona "no existe sino hacia los otros" (11). La persona es por naturaleza comunicable, evidencia que lleva a Jaspers a concluir que es en la comunicación que la existencia encuentra su ser al unirse con otro hombre, con otra persona y a Marcel a preconizar una filosofía de la inter-

(10) E. Mounier, "Manifiesto al servicio del personalismo", Taurus, Madrid, 1972, pág. 9.

(11) E. Mounier, "El Personalismo", păg. 20. 
subjetividad (12). De todo lo expuesto se hace patente que el primer acto de la persona es "suscitar con otras una sociedad de personas". No hay pues otro modo de concebir o pensar a la persona que en la dimensión comunitaria, como un ser estructuralmente social, existiendo y realizándose sólo en sociedad. La sociedad está asi dada en la estructura de la persona, integrando su más recóndito tejido. De ahi que es aberrante, artificioso y absurdo enfrentar - como todavia se pretende pese a tantos esclarecimientos producidos- a persona y sociedad como dos realidades estructuralmente diversas y contrapuestas.

IV. La Constitución de 1979 y la persona.

La Constitución $\mathrm{d}_{\mathrm{e}}$ 1979, por vez primigenia en el Perú regula en su Título I, en forma amplia, lo que designa como "Derechos y deberes fundamentales de la persona", introduciendo en su texto el vocablo persona que no habia sido antes adoptado ni por la Constitución de 1933 ni por el Código Civil de 1936 y que recién aparece, como hemos anotado, en el Proyecto de Código Civil elaborado por la Comisión instalada en 1965. El contenido de este Título I es, a nuestro entender, el aporte más sobresaliente de la Constitutción de 1979 ya que, por vez primera en la historia constitucional peruana, se incorpora a nivel de la Carta Magna, un conjunto de normas que sitúan a la persona como centro y término del Derecho.

El Capítulo I del Título I en mención se refiere especificamente a la persona. En su artículo primero declara textualmente que "la persona humana es el fin supremo de la sociedad y del Estado" y que "todos tienen la obigación de respetarla y protegerla". La Constitución inicia su articulado enunciando el principio juridico medular del personalismo, a partir del cual se abre una diáspora de derechos de la persona -denominados fundamentales o básicos- dignos de ser recogidos a nivel constitucional. Aparece asi el Derecho, en su imprescindible y cabal rol de "garante institucional de la persona", cumpliéndose la máxima suprema

(12) Karl Jaspers, "Ambiente espiritual de nuestro tiempo", Ed. Labor, Barcelona, 1933, pág. 164, y Gabriel Marcel, "El misterio del ser", Ed. Sudamérica, Buenos Aires, 1953, pág. 343. 
de que el Estado es para el hombre y no el hombre para el Estado (13). Insurge el Derecho como mediador necesario que normativamente "frena el egoísmo biológico, garantiza la existencia de cada uno, asegura en la jungla de los instintos y de las fuerzas el minimo de orden y de seguridad que permitirá los primeros injer. tos del universo personal" (14).

Si resulta inobjetable que el rol del Derecho, en cuanto ordenamiento juridico, es el de estructurar normativamente las mejores condiciones externas para el desarrollo y realización de la persona como ser libre dentro del bien común, no podemos ilusionarnos en que ello sea suficiente. Necesitamos batallar de continuo, estar vigilantes a fin que la norma vigente sea eficaz, tenga cumplimiento, se acate. $Y$ este es un problema crónico, arduo, constante como la historia, en tanto el homrbe, por ser libre, es impredecible. Nuestra experiencia nos muestra además los constantes fracasos de las mejores leyes cuando no son administradas por los mejores hombres. De ahi que, compartiendo la opinión de Mounier, consideramos que si bien el Derecho es de necesidad absoluta en cuanto mediador, en cambio es insuficiente para asegurar "una plena comunidad personal". un orden justo y pacifico, en el que el hombre pueda hacer una vida auténtica o egregia. Leyes optimas o sistemas teóricamente adecuados a tal propósito de nada sirven si una sociedad carece de un conjunto de hombres a nivel dirigencial que por su claridad, su entrega y su capacidad constituyan una solvente y eficaz garantia de que las aspiraciones valorativas comunitarias - traducidas en leyes- serán cumplidas al máximo posible y que la persona contará con las más convenientes condic'ones objetivas para su realización como tal.

La lectura completa del Título I de la nueva Constitución del Perú denota a las claras que en la Asamblea Constituyente que la elaboró existia un grupo de constituyentes compenetrado con las ideas matrices del personalismo, capaces de introducir en el texto de la Carta Magna aquel conjunto de principios rectores conreptuallizados y proclamados, entre otros, por el equipo de pensadores que se reunió en torno a la revista Esprit a partir de 1932.

(13) E. Muunier, "El Personalismo", pág. 62.

(14) E. Mounier, ob. cit., pâg. 24 
Nociones que, por lo demás y como lo hemos evidenciado, estaban ya recogidas en grandes tramos en el Proyecto de Libro Primero del Código Civil Peruano, antes referido, y en su correspondiente Exposición de Motivos.

\section{Los derechos fundamentales de la persona en la nueva Constitución.}

El artículo 2० del Capitulo I del Título I de la Constitución bajo comentario considera los llamados derechos fundamentales de la persona. Asi se despliegan a través de su articulado los derechos a la vida; al nombre; a la integridad fisica; al libre desenvolvimiento de la personalidad; al honor y la buena reputación; a la intimidad personal y familiar; a la propia imagen; a la inviolabilidad del domicilio y de los papeles privados y comunicaciones; a elegir el lugar de la residencia; a transitar libremente; a reunirse, asociarse, contratar con fines licitos; a escoger y ejercer libremente su trabajo; a la propiedad y a la herencia; a aicanzar un nivel de vida que permita a la persona asegurar su bienesta: y el de su familia; a participar en la vida politica, económica, social y cultural de la Nación; a guardar reserva sobre sus convicciones politicas, filosóficas, religiosas; a formular peticiones ante las autoridades; a la nacionalidad; a la libertad y seguridad personales. El último articulo, o sea el 4․, de este Primer Capitulo denominado "De la persona", explicita que la enumeración de derechos formulada por el artículo $2^{\text {o }}$ "no excluye los demás que la Constitución garantiza, ni otros de naturaleza análoga o que derivan de la dignidad del hombre, del principio de la soberania del pueblo, del Estado social y democrático de derecho.y de la forma republicana de gobierno". Cabe advertir que en este articulo se alude a la "dignidad del hombre", expresión de uso común en el léxico personalista para expresar la calidad de la persona como movimiento trascendente hacia un impersonal "que anuncia simultáneamente la experiencia de la comunión y la de la valorización" (15).

La suscinta numeración de derechos y libertades que hemos efectuado en el párrafo precedente, glosando el artículo $2^{\circ}$ de

E. Mounier, ob. cit., pág. 43. 
la Constitución (16), confirma el gran salto de calidad operado en el Perú en cuanto al Derecho Constitucional se refiere. Es motivo de legítima satisfacción saber que el Perú cuenta ya, a nivel constitucional, con un conjunto de normas que han sabido enfocar debidamente la situación de la persona en sociedad y en su relación con el Estado. Se ha superado, de este modo, el sentido vacío que se observaba en el ordenamiento juridico-normativo peruano, en el cual no existia, como lo hemos señalado, un plexo coherente y orgánico de reglas de derecho que protegiesen debidamente a la persona. $Y$ si a estas normas se agregasen, lo más pronto posible, aquellas otras que las desarrollan y que yacen insertas en el Proyecto del Código Civil -a la espera de su consagración legislativa desde 1967-_, el pais contaria quizás con el más completo repertorio de normas que, dentro del Derecho Comparado, están destinadas a la protección de la persona como fra supremo de la sociedad y del Estado.

Aparte del Capitulo I del Título I, la persona es frecuentemente mencionada e invocada a través de todo el texto del Título I, el mismo que está integrado por ocho Capítulos con un total de setentaiocho articulos. Ello ocurre, por ejemplo, cuando se señala que el Estado debe atender preferentemente sus necesidades básicas y las de su familia en materia de alimentación, vivienda y recreación; cuando en el caso de una deficiencia física o mental tiene derecho al respeto de su dignidad y a un régimen legal de protección, atención, readaptación y seguridad; cuando se prescrike que le es inherente el derecho a la educación y a la cultura. En todas estas situaciones la regla pertinente hace especifica mención a la persona como sujeto de los derechos.

VI. El trabajo y ia Constitución de 1979

Es interesante anotar que la Constitución de 1979 otorga al trabajo, en tánto expresión de la persona, una nueva y singu-

(16) No es del caso en esta oportunidad efectuar una critica de la sistemática y de la técnica legislativa empleada por el constituyente en el Capitulo I del Titulo I de la Constitución de 1979 como tampoco el realizar una comparación de todas y cada una de dichas normas con aquellas del Proyecto de Libro I "De las Personas" del nuevo Código Civil. No es tampoco la ccasión para emitir un juicio global sobre la entera Constitución. 
lar connotación conceptual. En su artículo 79 -trayéndonos una reminiscencia de la Constitución Italiana de 1947- declara que el Perú es una República basada en el trabajo, para señalar en el art. 76 que "todos contribuyen al bienestar general y a la realización de su propia personalidad mediante su trabajo como deber personal y social". Todo ello después de haber precisado, en el art. 42, que el Estado reconoce al trabajo como fuente principal de la riqueza y como un derecho y un deber social. Conceptos todos estos que son ratificados - para que no quede dudamediante el artículo 110 , el que establece que "el régimen económico de la República se fundamenta en principios de justicia social orientados a la dignificación del trabajo como fuente principal de la riqueza y como medio de realización de la persona".

Como fácilmente se aprecia de los artículos glosados en el párrafo precedente, la Constitución nos ofrece una rica, profunda y cabal conceptuación del trabajo, como factor de integración de la sociedad de personas, como basamento del Estado, como fuente principal de la riqueza $\mathrm{y}$, lo que es más importante, como medio para la realización de la persona. Es asi que el trabajo se despliega como instrumento de liberación de la persona que, como anota Mounier, "se libera liberando". Una liberación que se extiende a los otros, a la humanidad, y a las cosas, los que no deben ser colocados bajo la óptica de objetos susceptibles de ciominación o posesión sino, por el contrario, como entes a dignificar. Otros y cosas que no sólo --como lo veía Sartre (17) - son obstáculos para la realización de la persona sino que constituyen entes con los cuales la persona debe contar para hacer su vida, para realizarse. En esta dirección de pensaminto Mounier encuentra un avecindamiento entre el cristianismo y el marxismo. En efecto, "el movimiento del marxismo, que piensa que la misión del hombre consiste... en elevar la dignidad de las cosas humanizando la naturaleza, está aqui próximo al cristianismo, que da a la humanidad vocación de redimir por el trabajo, redimiéndose, a una naturaleza, que el hombre arrastró en su caída" (18).

(17) Jean Paul Sartre, "El ser y la nada", Tomo III, Buenos Aires, 1948. Analiza los obstáculos, las resistencias o dificultades que encuentra el hombre en la realización de su proyecto como ser libre. Ellos son, nuestra "facticidad" ("en sí") y el ser que nos imponen los "otros" y que nosotros no queremos ser, no decidimos ser ("la mirada").

(18) E. Mounier, "E1 Personalismo", pág. 17. 
No puede dejar de anotarse el profundo sentido didáctico de las nuevas normas del Titulo I incorporadas por la Constitución -y aquellas contenidas en el Proyecto de Código Civil-. las que, de ser debidamente divulgadas, contribuirán notablemente a la cabal formación humana y civica de las nuevas generaciones $y$ al surgimiento de un hombre politico rectamente concientizado. Por lo demás, el constituyente asi lo comprendió al establecer, en el tercer párrafo del articulo 22 de la Constitución, que la enseñanza sistemática de la misma "y de los derechos humanos es obligatoria en los centros de educación civiles y militares y en todos sus niveles".

Es de esperar que la enseñanza de la Constitución, a la par de transmitir lealtad para con sus normas, vaya acompañada de una cabal visión de lo que significa el ordenamiento normativo de un Pais, de su papel en relación con los otros dos elementos que integran el Derecho - y que se exigen reciprocamente- como sor: la vida humana comunitaria o social y el conjunto de valores o principios que tal comunidad se fija como ideal para su justa y pacifca convivencia. Que se informe debidamente que el Derecho e* fundamentalmente vida humana en relación, conjunto de seres coexistenciales, libres y dignos, que pretender vivir de acuerdo a ciertos valores a los que la comunidad aspira y para lo cual se requiere de un aparato normativo que traduzca y asegure todo ello. En este esquema la norma es instrumento para la realización de la persona como ser social. Es decir, en definitiva, que si bien es cierto que la norma vigente - $y$ en este caso la Constitución - debe ser acatada, ello no significa que tal norma deba permanecer inmóvil. estática, acabada, sino que, por regular vida humana -que es libertad, y por tanto, movimiento- debe ser continuamente confrontada - para su revisón, para perfección. para su cambio con la realidad de la persona en su dimensión social y con la vocación valorativa de la comunidad a fin de estructurar, cada vez mejor, la sociedad y el Estado al servicio de la persona.

La Constitución Peruana de 1979, informada de un aliento personalista y en mérito a todo cuanto de positivo hemos destacado, puede constituir un instrumento que, a través de las disposiciones 
de su Título I y de aquellos otros artículos que hemos glosado en estas páginas, contribuya a la creciente maduración civica y politica de la comunidad nacional y, mediante los proclamados pluralismo político y económico - arts. 68 y 112, respectivamente-. incentive la búsqueda de su identidad y propenda al diseño y consecución de una sociedad justa y solidaria para la más plena afirmación de los derechos fundamentales de la persona en un Estado cada vez más eficiente y auténticamente democrático. Todo ello contando con la diagonal y agónica vocación de perfección del hombre, concebida como la de una libertad combatiente que se yergue indómita y que subsiste aún en el fracaso sin doblegarse jamás. 